\title{
Alarms- Localization, Orientation, and Recognition
}

\author{
Marcus Sánchez Svensson \\ Hans Tap \\ Department of Human Work Science and Media Technology \\ Blekinge Institute of Technology
}

\section{INTRODUCTION}

In the beginning of the 1990s it was widely recognized that issues about how people work together and organize collaborative work was neglected in the considerations about how people use technology. From the recognition of the limitations of the traditional human-computer interaction paradigm a range of new design principles emerged. In 1990, Moran and Anderson proposed a new design paradigm, the workaday world (Moran \& Anderson, 1990). Their suggestion was to develop new design principles that could guide designers in embedding computers in a user's environment more firmly in ordinary work practices. This path has since then, for instance, been represented by concepts and technological innovations such as ubiquitous computing (Weiser, 1991), augmented reality (Wellner, Mackay, \& Gold, 1993), tangible bits, ambient media (Fitzmaurice, 1993; Ishii \& Ullmer, 1997), and mobile/wearable computing (e.g., Spreitzer \& Theimer, 1993).

One of the challenges for some of these new design principles, and particularly for ubiquitous computing, is the notion of calmness and comfort. Weiser and Brown (1997) pointed out in their notes on calm technology that it will be crucially important in design work to consider how smart devices and disappearing computers are going to engage users' attention.

In this light, this article presents an ethnographic study in which our analysis attempts to address some of the implications of distributing or embedding information technology in the users' work environment. This study focused on the use of different alarm systems at three dialysis departments. The character of the design of the alarm systems is to some extent in line with the visions of ubiqui-

We thank Berthel Sutter, Bo Helgeson and Sara Eriksén for readings and helpful suggestions with our article.

Requests for reprints should be sent to Marcus Sánchez Svensson, Work, Interaction and Technology Research Group, The Management Center, King's College London, Franklin-Wilkins Building, London SE1 8WA, UK. E-mail: marcus.sanchez svensson@kcl.ac.uk 
tous computing. The alarm devices in the technical system are distributed in the environment to make notifications and indications about alarms available for nurses in many places at the department. This study has raised a range of questions that are relevant for research on how to embed technology in the users' environment, such as the integration of information in physical space (e.g., Cooperstock, Tanikoshi, Beirne, Narine, \& Buxton, 1995; Streitz, Geissler, \& Holmer, 1998) and issues on peripheral awareness (e.g., Bly, Harrison, \& Irwin, 1993; Pedersen \& Sokoler, 1997; Sawhney \& Schmandt, 1998). On the issue of designing for calmness and comfort, we wish to explore how the affordances of the different alarm systems, concerted in the nurses' physical environment, come into play in the actual accomplishment of work.

Even though it is not the main concern, this article also contributes to the growing body of research on alarm design and the use of alarm systems in different work settings. This research has been represented by studies and experimental work in process control rooms (Hollywell \& Marshall, 1994; Stanton, 1994; Woods, 1995), intensive care units (Edworthy, 1994; Kerr \& Hayes, 1983; Meredith \& Edworthy, 1994), operating theatres (Kesting, Miller, \& Lockhart, 1988; Momtahan, Tansley, \& Hetu, 1993; Patterson, Edworthy, Shailer, Lower, \& Wheeler, 1986; Seagull \& Sanderson, 1998), and in civil aircraft (Patterson, 1982). Many of these publications, especially those from the field of human factors, have been concerned with the audibility, discriminability, and identifiability of alarms (Edworthy, 1994; Momtahan et al., 1993; Patterson et al., 1986). These studies have also raised issues about the appropriateness of certain alarms in settings such as operating theatres and intensive care units. It has, for instance, been recognized that the increasing number of audible alarms in operating theatres and intensive care units increases the risk of confusion as to the source of the alarm (Kerr \& Hayes, 1983; Meredith \& Edworthy, 1994).

To begin with, a background to our study and the methodological approach are presented. A short description of the work at the dialysis departments and the different alarm systems in use are then provided. Aspects of work practice and technology in use are of central concern, such as how labor is divided among the nurses, how they incorporate technology in their decisions, and how technology influences their collaboration (Tap \& Svensson, 1999). We have observed that the nurses are often in motion, moving from room to room, attending patients, handling medical tools, doing administrative work, and fetching materials. This aspect of their work puts a demand on the design of alarm systems in terms of how they should present different alarms to the nurses to engage their attention without interfering with their current work tasks. The analysis of the alarm systems in use addresses how the properties of the specific alarm systems, located in the local physical environment of the dialysis department, afford localization, orientation to, and recognition of alarms. In this article, localization is about the ways in which the nurses exactly locate where the alarm comes from and orientation is how the nurses orient themselves toward the alarm in a less precise way. Recognition is about how the nurses notice that there is an alarm in the first place and if there are multiple alarms. The article ends with a set of design considerations in respect to localization, orientation to, and recognition of alarms when designing future systems. 


\section{BACKGROUND}

For the last two years, we have been involved in a research project in collaboration with the county council, the county hospital, and a medical company. In this project we are interested in how medical staff and patients actually use different technological tools within dialysis treatment and how this understanding might influence the design and development of new technological tools.

Our field material is mainly based on observational studies inspired by traditional ethnographic methods, but in the examples presented in this article, video-based interaction analysis is also used (Ruhleder \& Jordan, 1997). Our approach is based on the importance of getting a deep understanding of the social context in which the system is going to be placed. We are interested in how people actually go about doing their work and how they actually use information technology. We believe that an understanding of people's practical circumstances in the use of technology may constitute good conditions for the design of new technological artifacts.

The results in this article are based on ethnographic field studies at three dialysis departments (although only two will be presented in this article). Video recordings at the departments were complemented with notes about nurses' engagement in the alarm situations not visible on the videotapes. Our understanding of the nurses' use of their alarm system has to some extent also evolved during the nurses' active involvement in workshops and design activities.

\section{THE ALARM SYSTEMS IN USE}

Before continuing with the analysis and discussion, we will firstdescribe the alarm systems, dialysis departments, and way in which these features in the nurses' work.

At the dialysis departments, the nurses treat approximately 16 patients a day who have renal disease. In a normal shift, about four nurses take care of eight patients and each nurse is mainly responsible for two patients. The dialysis department is divided into patient rooms, lunchroom, offices, kitchen, and storage rooms on both sides of a
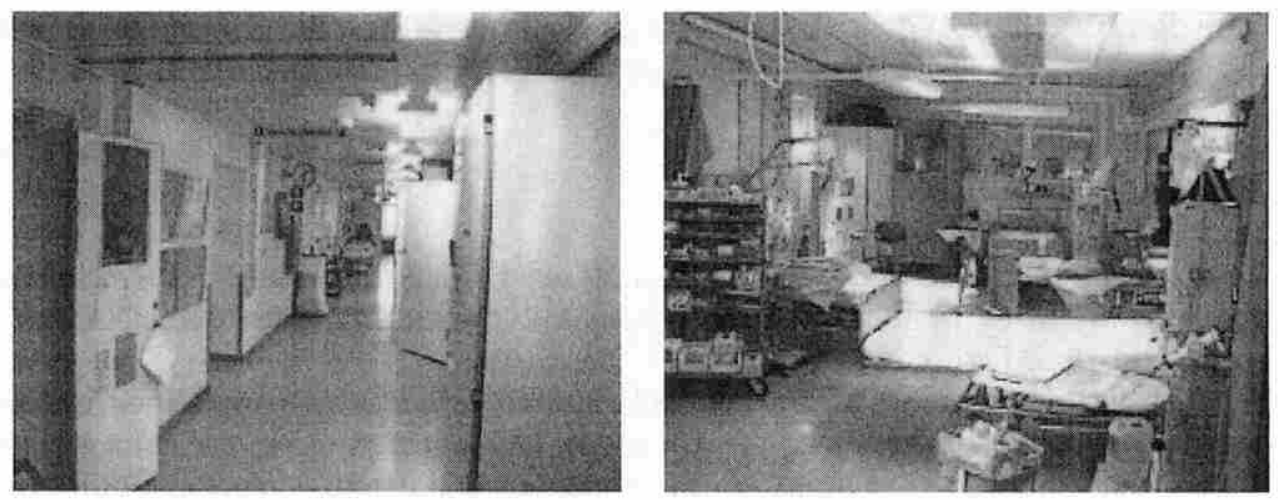

FIGURE 1 The corridor (left) and a patient room (right). 
long corridor (see Figure 1, left). In the patient rooms, where the patient receives dialysis treatment, the space is occupied by patient beds, dialysis machines, tables with medical tools, chairs, and television screens (see Figure 1, right).

In the morning when the patients arrive, they go to their specified bed where a nurse sets up the dialysis machine and connects the dialyzer (which purifies the blood and serves as an artificial kidney) to the patient. When the treatment is started, the two main functions of the dialysis machine are to pump blood from the patient through the dialyzer and back to the patient again, and to supervise and control the process. For example, if the dialysis machine detects a high arterial pressure it stops the blood pump and activates an alarm indication.

The most important task for the nurse is to maintain and supervise the patient's physical condition during treatment. However, there are certain tasks at the departments that make it impossible for the nurses to stay at the patient's bedside during the treatment. The nurses have to deal with paperwork in the office as well as answering phone calls, assisting other nurses, fetching materials from the storage rooms, or having their lunch and breakfast in the lunch room.

The dialysis machine and the alarm system enables the nurses to attend to other work tasks while still being responsible for their patients. In the patient rooms in all dialysis departments, each dialysis machine has its own alarm device that simultaneously indicates an alarm by an audible signal and a visual indication. In addition, all patients have a patient alarm device beside their bed that they can use to get the nurses attention. However, because of the physical layout of the building, the organization of the dialysis departments, and the character of the nurses' work practice, the alarm indication in each patient room is not sufficient. To ensure the alarm will be heard, the notifications and indications are propagated to other parts of the department. Each dialysis machine and patient alarm is connected to a distributed alarm system that thus makes the visual and audible resources available in other parts of the department as well.

The remaining part of this article focuses on the distributed part of the alarm system and the ways in which nurses receives notification of the alarms. All alarm systems described in this article have the same purpose and features as those described. In the following sections the differences between alarm systems are described. Although three different systems have been studied, only two of them are described here. A description of the third alarm system can be found in a previous study conducted by Sánchez Svensson, Tap, \& Selling Sjöberg (2000).

\subsection{Alarm System A}

At one of the dialysis departments the staff used an alarm system that was implemented in 1987. This alarm system (system A) is the oldest of the three included in this study (see Figure 2).

The alarm system has an alarm panel outside each patient room in the corridor, and a room panel inside each patient room. The alarm panel in the corridor has three alarm lamps: a red lamp for the indication of a machine alarm, another red lamp for the indication of a patient alarm, and finally a white lamp indicating the presence of nurses in the patient room (see Figure $2 \mathrm{~b}$ ). Inside the patient room, the 


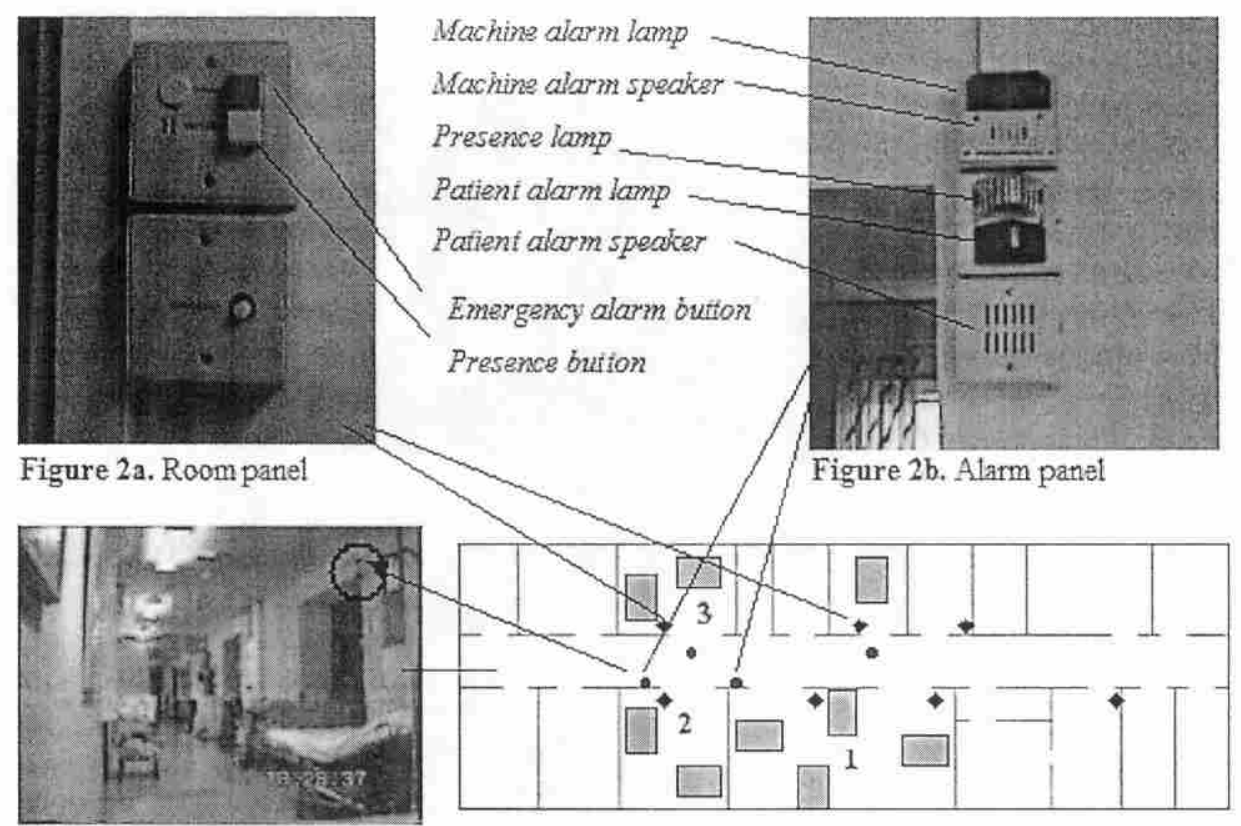

FIGURE 2 Alarm panel and room panel in alarm system A

room panel has two buttons: a red emergency button for emergency alarms and a white presence button for the indication of presence (see Figure 2a).

When an alarm is activated on the dialysis machine, the alarm lamp on the alarm panel outside the patient room starts to flash with a red light and the machine alarm speaker in the corridor sends out an audio signal. The alarm panel has the same activation interval as the dialysis machine, which reactivates the alarm signal once a second until it is reset.

The second red lamp on the alarm panel-the patient alarm-turns red and a centrally positioned patient alarm speaker (see Figure $2 \mathrm{~b}$ ) sends out one audio signal when the patient alarm button in the patient room is pressed (see Figure 2a). This patient alarm is re-activated every $10 \mathrm{sec}$.

On the alarm panel, the white alarm lamp is turned on whenever a nurse presses the presence button on the room panel. The purpose of this function is to enable nurses to inform other members of the department that somebody is present in the room. Another feature is the emergency alarm that a nurse activates by pressing the emergency button on the room panel. Also, if the presence indication has been activated, pressing the patient alarm button will cause an emergency alarm. On the alarm panel in the corridor, the emergency alarm is indicated with a red flashing light from the patient alarm lamp and a sound from the machine alarm speaker.

Figure 3 is a video fragment from alarm system A that demonstrates the functions and the use of the alarm system. The alarm situation that unfolds in this fragment starts with an alarm indication from patient room 1. 


\section{$18: 28: 31$}

An alarm is acivated in patient room 1. The alarm lamp flashes on the alarm panel and the speater sends out an culio signal that is repeated

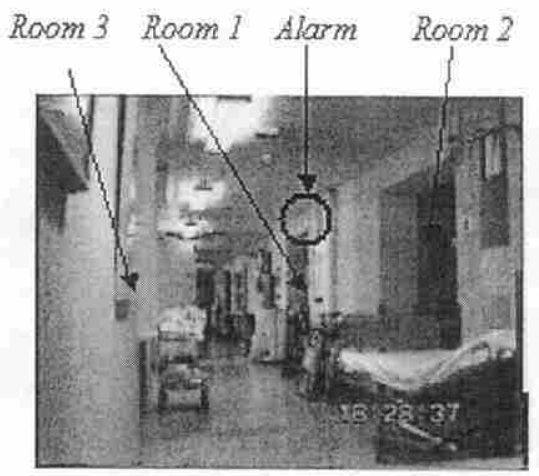

At this moment murse $B$ is in room 1 , nurse $A$ in room 2 to the right and nurse $C$ is in room 3 on the left side of the corridor

\section{$18: 28: 38$}

Nurse A takes a conple of steps out into the corridor. Before he enters the corriabr he furns his head fow ar d room one.

\section{8:28:39}

The alarm panel continues to indicate the alarm from room one Nitrse $A$ stops in the mialde of the corriator and

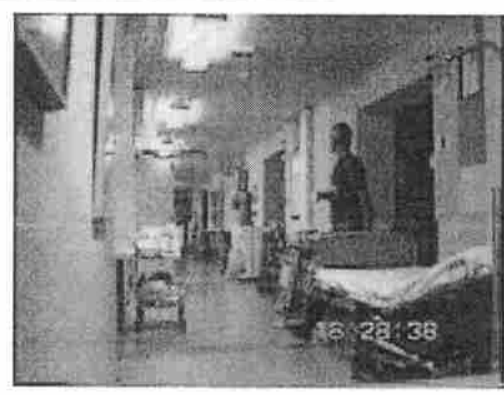
furns his boat iowards room one At this moment Nurse $C$ appears in the corridor from room thres.

\section{8:28:40}

Also Nurse B totes a lach in the corridor stanaing in the entrance to the patient room Nurse $A$ stanaing in the corridor points at nurse $B$.

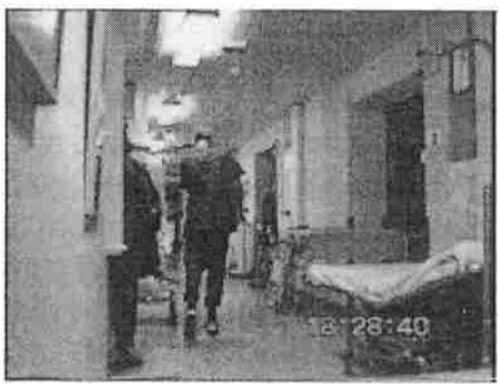

FIGURE 3 Alarm situation in alarm system A.

In the first part of an alarm situation, a dialysis machine in patient room 1 activates an alarm and the distributed alarm system activates the alarm in the corridor about 5 to $6 \mathrm{sec}$ before nurse A enters the corridor. When nurse A enters the corridor, he already focuses his attention toward room 1 . When he notices nurse B, he turns around and points at her.

What is particularly interesting is how the alarm situation unfolds and the way in which all three nurses appear in the corridor. This alarm situation posed a range of questions for us and later in this article this fragment in our analysis of how the properties of the environment and the alarm system are made available for the localization, orientation to, and recognition of alarms is discussed. 


\subsection{Alarm System B}

The second alarm system (system B) is used at a dialysis department operating since 1996 (see Figure 2). As in the previous alarm system, this one also consists of alarm panels in the corridor and room panels distributed within the department. What is different, compared to alarm system A, is how the alarm indication is distributed and presented.

Along the department corridor, three alarm panels are mounted in the ceiling (see Figure 4). Each alarm panel consists of a display and a hidden speaker (see Figure $4 \mathrm{~b}$ ). In contrast to the older alarm system A, every alarm indication is distributed to all alarm panels simultaneously. Inside each patient room the room panel is located just beside the entrance. These room panels have an alarm display, an emergency button, and a presence button (see Figure 4a). Other rooms at the department have a room panel as well, but those panels do not have an emergency button.

The indication on the alarm panel provides the nurse with information about room location, patient bed, and alarm category. In case of a machine alarm from patient 3 in room 2, the text " $2-\mathrm{d} 3$ " (" $\mathrm{d}$ " stands for dialysis machine) will appear in the display on the alarm panel. If it is a patient alarm indication, the display would instead present the text "2-3." Both patient alarm and machine alarm are indicated with three audio signals from the speakers. If there are two or more alarm indications at the same time, the display will show the multiple alarms by switching between them continuously. If the alarm is not reset after about $15 \mathrm{sec}$, the alarm is reactivated again with three audio signals.

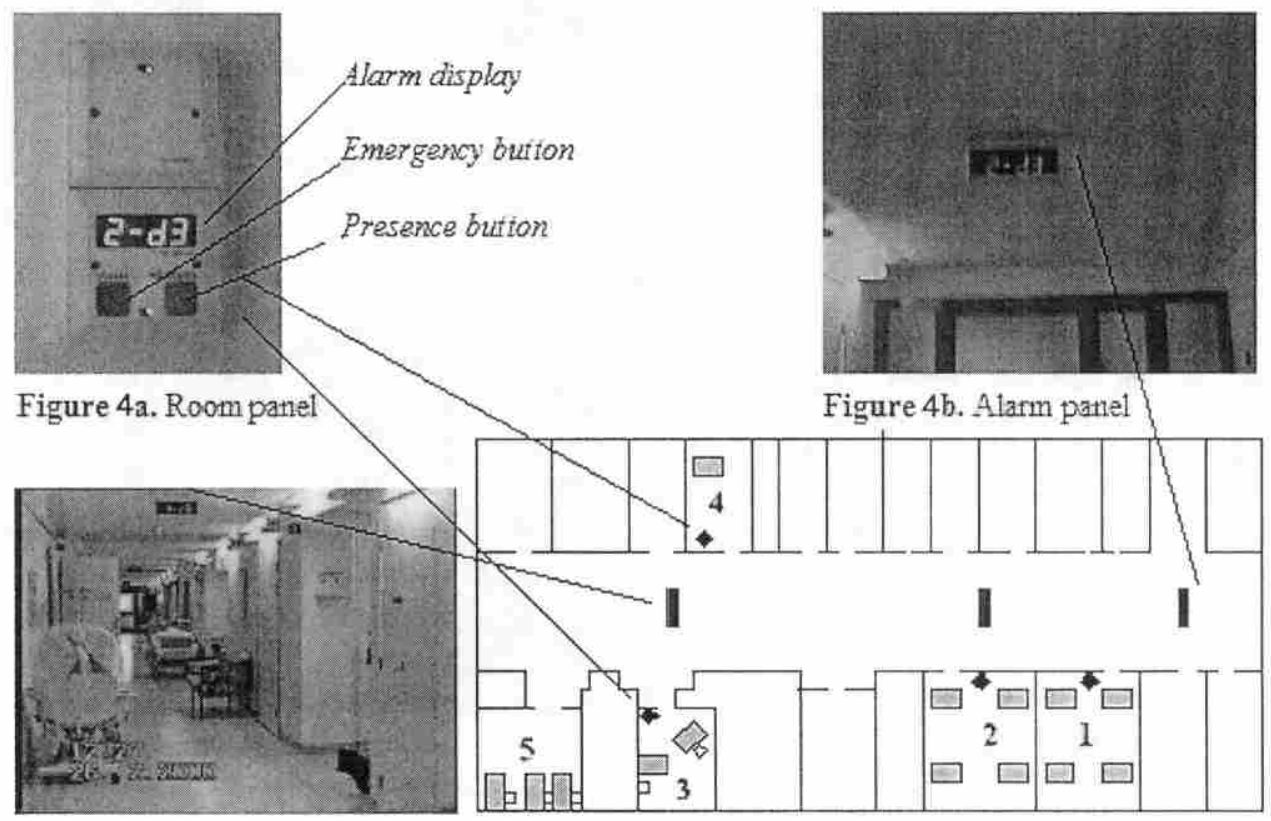

FIGURE 4 Alarm panel and room panel in alarm system B. 
If nurses wish to be notified about the alarm through the room panels in patient rooms, they need to press the presence button. The purpose of this design decision is to allow nurses to decide if they want to get alarm indications from other parts of the department in the patient room. Normally the nurses do not want to disturb the patient with this alarm indication.

When an emergency alarm is activated in this alarm system, the text on the display flashes continuously and the speaker sends out an alarm sound that differs from the other and reactivates each sec until the alarm is reset. The emergency alarm is activated if the emergency button located beside each patient bed is pressed or if the patient alarm button is pressed when the presence button has already been selected (in the same way as in alarm system $\mathrm{A}$ ).

The video fragment in Figure 5 demonstrates the use of alarm system B. It shows a situation where several alarms are activated from three different patient rooms and how they engage the nurses' attention.

12:14:05 An alarm from room 2 is activated and ine alarm ditplay in the corrider reads "2-d1". Also three audio signal indicates the alarm.

12:14:12 Nurse A enters the corridor from the kitchen and goes directly ino portient room 2.

12:14:13 When nurse $A$ is on her way in the corridor another alarm from room 5 is presented on the alarm display. The text "5d3" appears on the display and indicated by: an audio signal. Alorm "2-dl" and " $5-d \mathrm{~s}^{2}$ is altered on the displays in the corridor ever: second

12:14:24 Nurse $B$ enters the corridor and walks roward patient room 5.

12:14:31 In the same moment as nurse $B$ enters the patient room anotiner alarm appears in the alarm system In emergency. alarm is inticared and the alarm displays reads "3-2". The texs flarines and repears the audio signal continusuty. Lis oiner alarms but the emergency alarm is presented on the displass.

12:14:53 Nurse $C$ comes out from the kirchen and nurries iowar ds pariens room $j$ and as she enters the room she says: "Tes. yes, yes".

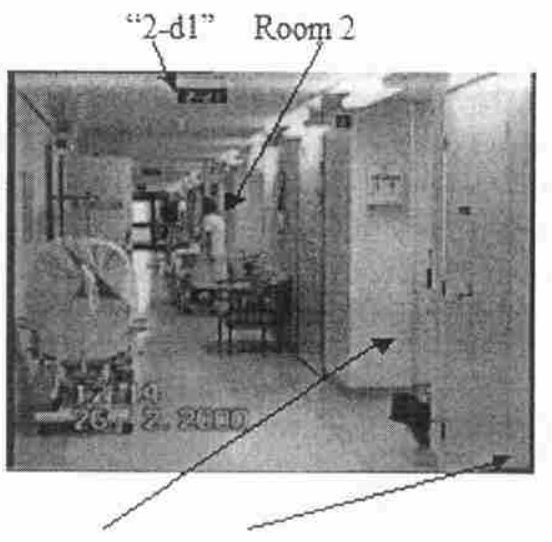

Room 3 Room 5

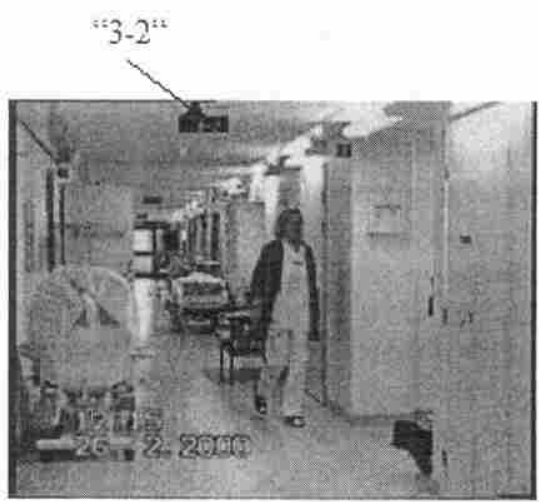
Shorth afierward the alarm it reser and all three nurses reswn to the kitcinen

FIGURE 5 Alarm situation in alarm system B. 
The fragment shows how alarm indications are presented on displays in the corridor and the way audio signals notify the nurses about alarms. However, what makes this fragment more interesting, which will be discussed later, is the use of the room panels inside the kitchen and the patient rooms. In the kitchen the nurses usually activates the presence indication during the whole day. They do this because nobody other than themselves is disturbed by the alarms in the kitchen. The alarm indications in the kitchen also simplify the division of alarm management between the nurses during breakfast and lunches. However, what also is apparent in the alarm situation is the occurrence of an emergency alarm. The presence button was activated earlier during the morning in patient room 3 . Because the presence indication on the room panel still was selected, the emergency alarm was activated when the patient pressed the patient button. This alarm situation provides an example of the way in which the room panel affects the localization and recognition of alarms. In the next section this example is discussed further.

\section{AFFORDANCES OF THE ALARM SYSTEMS}

There are several issues that are interesting to analyze in this case study, but this article focuses on two topics related to the design of the different alarm systems. The first topic concerns localization and orientation-how the alarm systems indicate where the alarms are coming from. The second topic is a discussion of the different characteristics of the alarm systems in relation to how alarms are recognized and distributed. The analysis on these topics draws partly on Gibson's ecological approach on perception, particularly the concept of affordance (Gibson, 1979). The alarm systems' characteristics, how they differ from one another, and what they offer to users in different alarm situations are discussed in the following. The first topic we have selected concerns localization and orientation-how the alarm systems indicate where the alarms are coming from. The alarm systems have different approaches that afford different kinds of use for the nurses. The second topic, affordance, is a discussion of the different characteristics of the alarm systems in relation to how alarms are distributed and recognized.

\subsection{Localization and Orientation}

One obvious and important role of an alarm system is how it enables users to locate an alarm. Nurses need to determine in what direction they have to walk and if the alarm is their responsibility. The alarm systems we have studied relate to this problem in rather different ways. First a description of how alarm system A is designed to solve these problems is provided.

As seen in the system description, one alarm panel is placed in the corridor outside each patient room. When an alarm is propagated from the patient room to the corridor, the alarm lamp and the speaker placed outside that particular room are activated. Nurses standing in the corridor might locate the alarm quickly because of the direct relation between the patient room and the alarm panel outside the 
room. They might also locate the alarm by the alarm sound from the speaker placed outside each patient room. From the office, the lunchroom, or other parts of the department, the alarm system makes it possible for the nurses to hear if the alarm originates from far down the corridor or from a room nearby. This alarm system uses the physical placement of the alarm as a way of orienting the nurses to the alarm source - both by audible and visual effects.

Now turning to an example of the special features of alarm system $\mathrm{A}$ in this respect, the video fragment presented in the demonstration of alarm system A (see Figure 3) illustrates the use of audio and visual orientation. In the first part of the alarm situation it is noticeable how nurse A focuses his attention on room 1 immediately as he enters the corridor (see Figure 6). Through the placement of the sound source, he is able to determine rapidly the direction of the alarm. He turns around and looks at the alarm panel, notices nurse B in the entrance to room 1, and points in her direction. However, although the alarm is activated in nurse B's own patient room (the dialysis machine also indicates the alarm by the patient bed), the nurse does not recognize the alarm signal. In this alarm situation she obviously did not catch if the alarm signal was coming from the alarm panel outside her room or from the other two alarm panels in the corridor. The nurses have told us that they sometimes become disoriented by the repeating alarm signals in the corridor, the alarm indication from the dialysis machine and medical equipment, and noises from radios and televisions in the patient rooms.

As in alarm system A, alarm system B also has alarm panels in the corridor. However, alarm system $B$ does not enable nurses to locate the alarm by the physical placement of the alarm panels. Instead this information is coded on displays. Alarm system B uses displays where a couple of letters and numbers state the localization of the alarm (see section 3. The Alarm Systems in Use), e.g. "3-1" should be interpreted as an alarm from patient room 3 at bed 1 . Whenever a new alarm is activated, the system both indicates the alarm on the display and sends out a short sequence of audio signals.

Though alarm system B does not use the physical placement as an orientation toward the origin of the alarm, it supports the nurses' localization of alarms in a more specific way than does alarm system $\mathrm{A}$. The alarm lamp on the alarm panels in


FIGURE 6 The nurse's shift of orientation and the nurses' localization of the alarm. 
alarm system A only identify the patient room, but in alarm system B the indication of patient bed is also identified.

One apparent difference between the alarm systems is the way in which alarm system A makes it possible to hear in what direction the alarm is coming from. In the other alarm systems, the alarm indication is replicated on all alarm panels. The only way to know where the alarm has its origin is to read the letters and numbers on the display and know what the text stands for. In alarm system A, the physical placement of the alarm indication in the corridor makes it more obvious from where the alarm has its origin for anyone who happens to be in the corridor. The audio signal in alarm system B is only used for getting the nurses' attention and not as guidance for localization or orientation.

\subsection{Alarm Recognition}

The nurses not only need to know where to go when an alarm is activated, they also need to be notified that there is an alarm in the first place. It is also relevant to recognize if there is more than one alarm active at the same time. In this section, a discussion of how these problems are handled in the different alarm systems is provided. First we consider an example from alarm system B.

When the first alarm is activated (see Figure 7), there is a sound from the alarm panel and a description of the alarm is shown on the display. About every 15 to 18 $\mathrm{sec}$, the alarm is re-activated with a sound. At first this is rather unproblematic, but

FIGURE 7 Example of multiple alarm indications from alarm system $B$.

\begin{tabular}{|c|c|c|c|}
\hline Time & Display & Sound & Comments \\
\hline $45: 13$ & 2-d1 & 3 beeps & $\begin{array}{l}\text { New machine alarm } \\
\text { indicated }\end{array}$ \\
\hline$: 28$ & & 3 beeps & $\begin{array}{l}\text { Alarm re-indicated by } \\
\text { sound ( } 2-d 1 \text { constantly }\end{array}$ \\
\hline$: 46$ & & 3 beeps & visible on the display) \\
\hline $46: 05$ & $1-\mathrm{d} 3$ & 3 beeps & $\begin{array}{l}\text { New machine alarm } \\
\text { indicated }\end{array}$ \\
\hline$: 07$ & 2-d1 & & \\
\hline$: 10$ & $1-\mathrm{d} 3$ & & \\
\hline$: 13$ & 2-d1 & & $\begin{array}{l}\text { The display alternates } \\
\text { between active alarms }\end{array}$ \\
\hline$: 16$ & $1-d 3$ & & \\
\hline$: 19$ & 2-d1 & & \\
\hline
\end{tabular}


at 46:05, when a new alarm is activated, a possible problem begins to appear. The only difference in indication from the alarm system is the new display indication "1-d3." The sound indication for the new alarm can be perceived as yet another reactivation of the " $2-\mathrm{d} 1$ " alarm. The intervals between the beeps are the same as before, so the sound will not hint to nurses that a new alarm has been activated. They need to look at the display to get the information. For example, assume that a nurse glances at a display one sec after the three beeps when the display information shows "2-d1." One possible interpretation from the nurse is that it was just another reactivation of the "2-d1" alarm. In this example, the nurse has to look at the display for about four sec before she knows if the sound was indicating a new alarm or reactivating an old one. If there are two active alarms, she has to wait for about seven seconds (worst case) to be sure. If the nurses are able to look at the display within 2 to $3 \mathrm{sec}$ (during the three beeps), the alarm indicated on the display is the actual alarm that causes the beeps.

This example describes a kind of sequential notification that only allows one alarm to be visible at a single moment. With alarm system $\mathrm{A}$, the design provides another kind of alarm distribution, namely parallel notification. The alarm panels in alarm system $A$ are independent of one another, so more than one panel can be active at one single moment. This has the effect that more than one alarm can be heard and seen at the same time - the nurses get not only an orientation toward the alarm, they also hear if there are multiple alarms. This can be useful when they are busy with other tasks, because they might continue with whatever they were doing and still know if there is more than one alarm and possibly also hear where it originates.

There are, however, some obvious disadvantages with the parallel distribution (as designed in alarm system A). Alarm system A is noisier than the other two, and, when adding the sound from televisions and phones, there is sometimes a hullabaloo of different sounds. The alarm situation described in Figure 3 gives an example of such an event. This is more seldom the case when using alarm system B, because only one alarm is indicated at a single moment. Also, the volume of the sound from system $\mathrm{A}$ is higher than with the other system because the sound needs to be distributed through the whole corridor from one single audio source.

\subsection{Distribution of Alarm Devices}

Another issue about the alarm systems not yet considered is the way in which alarms are made available for the nurses inside the patient rooms. As seen in alarm system A, there are many benefits of having the audio signals sent out from the physical location of the alarm source. The problem, however, is the need for a rather high sound volume to make the audible alarm signals available to the whole department. Instead of having a louder sound in the corridor, the nurses using alarm system $B$ have the choice of deciding if they want to distribute the alarm indication to the patient rooms by using the presence button on the room panels.

In our field study, we were able to observe an event in which two nurses were occupied with a patient in one of the patient rooms. The patient was about to get connected to the tubes from the dialysis machine. The nurses assisted each other insert- 
ing the needle into the patient, handing over the blood tubes and dealing with the dialysis machine. At this moment an alarm was activated in a patient room further down in the corridor. The nurses in ward 4 heard a couple of alarm indications from the corridor and realized that they had not pressed the presence button on the room panel, which otherwise would have made it possible for them to see the alarm indication on the display in the room. The situation was complicated further by the fact that they could not easily drop their work to press the presence button on the room panel or take a step out into the corridor to inspect the display.

In addition to this example, the video fragment from alarm system B (see Figure 5) provides a nice contrast. In the situation that the video fragment illustrates, the presence button was still selected even though there was no nurse present in the patient room. Simply, the point we wish to make is that in alarm system B the presence button is an interface for the distribution of the alarm indications inside the patient room. But at the same time the presence indication is also a state in the alarm system that activates an emergency alarm if a patient is calling for help from the same patient room even if a nurse is not present. Both of the situations described demonstrate an example of the possible implications of the distribution of information in physical space and the problems of how to inform the user in a seamless and unobtrusive manner. In the first situation, the nurses in the patient room were notified and able to recognize the alarm, but were unable to localize the origin of the alarm because of the practical circumstances. In the second situation, the nurse was able to localize the alarm on the room panel inside the kitchen, but for this particular situation the emergency alarm signaled an incorrect level of urgency from the patient room.

\section{CONCLUDING REMARKS}

This article contributes to research on ubiquitous computing and demonstrates the implications of deploying systems and technologies that are distributed and ubiquitously embedded in the users' environment. In that respect, the principal theme in this analysis concerns how the alarm systems and the properties of the environment afford localization, orientation to, and recognition of alarms.

This study demonstrates that nurses use sound and visual effects in several different ways. The corridor displays in the alarm systems give nurses exact information about the location of the alarm. In the older system, nurses can determine the location of the alarm by looking down the corridor to see which alarms were active in direct relation to the patient room and then look inside the room to see which dialysis machine was indicating the alarm. Sound, on the other hand, may provide users with other information. In this study, it was observed that sound tells users where to look. Sound has affordances that provide users with a peripheral awareness of events and other people (Gaver, 1997), allowing their attention to move back and forth between center and periphery (Weiser \& Brown, 1997). At more distant locations, nurses can hear and orient themselves toward the alarm with the possibility of attending to the current work task while being aware of the alarm activation at the same time. 
For the purpose of summarizing this article, some of our central observations and findings are presented in Table 1 . As much as the character of the analysis in this article is shaped by a limited set of issues and settings, this list of findings is not in any way a set of recommendations or guiding rules for design work. These particular findings have to be considered in relation to an understanding of the local circumstances of the setting in which the technological system is going to be introduced. Furthermore, being able to produce recommendations or requirements would, in our view, demand a further explication and investigation of aspects such as collaboration and communication.

There is a range of technological innovations and design considerations that could be interesting for the design of future alarm systems and for other kinds of technological systems embedded in the users' environment. In the literature on alarm design, urgency levels and acoustically designed warning signals (i.e., Patterson et al., 1986) have been suggested. Gaver conducted a similar study on the use of auditory interfaces (Gaver, 1986, 1991) and pointed to the problems of using arbitrary sound mappings in intensive care units (Gaver, 1997). Furthermore, in recent and earlier research on augmented reality, ambient media, and ubiquitous computing, a growing number of design ideas and innovations, such as wearable auditory displays (Sawhney \& Schmandt, 1998), active badge systems (Spreitzer \& Theimer, 1993), and reactive environments (Cooperstock et al., 1995), has been demonstrated and suggested as possible ideas for the problem of information provision and engagement of attention.

In contributing to this research and design work, along with our findings presented in this report, we made an interesting observation. We found that alarm

Table 1: Summary of Observations and Findings

\begin{tabular}{|c|c|}
\hline Properties & Effects \\
\hline \multicolumn{2}{|l|}{ Alarm System A } \\
\hline \multirow{2}{*}{$\begin{array}{l}\text { Physical placement: Independent alarm } \\
\text { panels outside each patient room }\end{array}$} & Peripheral orientation (both audible and visual) \\
\hline & $\begin{array}{l}\text { Obvious from where the alarm has its origin (no need } \\
\text { to read text on a display) }\end{array}$ \\
\hline Audio signals and visual indications & $\begin{array}{l}\text { Getting the nurses' attention and orienting them } \\
\text { toward the alarm source }\end{array}$ \\
\hline \multirow[t]{2}{*}{ Parallel alarm indication } & $\begin{array}{l}\text { Multiple alarms can be heard and seen } \\
\text { simultaneously }\end{array}$ \\
\hline & Noisy \\
\hline \multicolumn{2}{|l|}{ Alarm System B } \\
\hline \multirow[t]{2}{*}{$\begin{array}{l}\text { Physical placement: Same alarm indication } \\
\text { distributed to every alarm panel }\end{array}$} & $\begin{array}{l}\text { Demand a focused attention to read the text on the } \\
\text { alarm panels }\end{array}$ \\
\hline & Not as guidance for localization and orientation \\
\hline \multirow[t]{2}{*}{ Audio signals and text indications } & Getting the nurses' attention (audio signals) \\
\hline & Affords localization (text) \\
\hline \multirow[t]{2}{*}{ Sequential alarm indication } & $\begin{array}{l}\text { Demand a continuous attention towards the alarm } \\
\text { display in order to recognize multiple alarms }\end{array}$ \\
\hline & Recognition of multiple alarms takes time \\
\hline $\begin{array}{l}\text { Selectable alarm indication in patient } \\
\text { rooms }\end{array}$ & $\begin{array}{l}\text { Demand activating the presence button in order to } \\
\text { receive alarms in the patient rooms }\end{array}$ \\
\hline
\end{tabular}


system A sometimes produces alarm signals that end the indication with a discordant sound. This is an interesting effect in the older alarm system that is not based on a conscious design decision but is rather due to the older technology being used. Although the closure sound could be seen as an unsuccessful design, we believe it is something one could use and deliberately include in the design of an alarm system, and especially if included in a system using sequential notification. By using a special sound as the prelude for a new alarm, and a closure sound when an alarm is terminated, one can imagine that the necessary attention focused toward the displays might be reduced. For instance, nurses could continue with their task and just by listening to the alarms determine if it is a new alarm or a reactivation of an old one.

Furthermore, another interesting aspect is the comparison between parallel and a single distribution of alarms. By having a parallel distribution, nurses get a feeling about how busy it is in the different patient rooms. With the single alarm indication, there is a possibility that many alarms will become invisible and unseen for the majority of the nurses. By including prelude and closure sounds to the sequential notification systems there is at least a chance of being aware of the number of different alarms.

\section{REFERENCES}

Bly, S., Harrison, S., \& Irwin, S. (1993). Media space: Bringing people together in a video, audio, and computing environment. Communications of the ACM, 36, 28-47.

Cooperstock, J. R., Tanikoshi, K., Beirne, G., Narine, T., \& Buxton, W. (1995). Evolution of a reactive environment. Proceedings of CHI '95 (pp. 170-177). New York: ACM Press.

Edworthy, J. (1994). Urgency mapping in auditory warning signals. In N.A. Stanton (Ed.), Human factors and alarm design (pp. 15-30). London: Taylor \& Francis.

Fitzmaurice, G. (1993). Situated information spaces and spatially aware palmtop computers. Communications of ACM, 36, 38-49.

Gaver, W. W. (1986). Auditory icons: Using sound in computer interfaces. Human-Computer Interaction, 2, 167-177.

Gaver, W. W. (1991). Sound support for collaboration. In Proceedings of the Second European Conference on Computer-Supported Collaborative Work, 1991 (pp. 293-308). Dordrecht, The Netherlands: Kluwer Academic.

Gaver, W. W. (1997). Auditory interfaces. In M. G. Helander, T. K. Landauer, \& P. Prabhu (Eds.), Handbook of human-computer interaction (2nd ed., pp. 1003-1041). Amsterdam: Elsevier Science.

Gibson, J. J. (1979). The ecological approach to visual perception. New York: Houghton Mifflin.

Hollywell, P. D., \& Marshall, E. C. (1994). An experiment to support the design of VDU-based alarm lists for power plant operators. In N. A. Stanton (Ed.). Human factors and alarm design (pp. 31-44). Bristol, PA: Taylor \& Francis.

Ishii, H., \& Ullmer, B. (1997). Tangible bits: Towards seamless interfaces between people, bits and atoms. In Proceedings of CHI '97 (pp. 234-241). New York: ACM Press.

Kerr, J. H., \& Hayes, B. (1983). An "alarming" situation in the intensive therapy unit. Intensive care medicine, 9, 103-104.

Kesting, I. G., Miller, B. T., \& Lockhart, C. H. (1998). Auditory alarms during anesthesia monitoring. Anesthesiology, 69, 106. 
Meredith, C., \& Edworthy, J. (1994). Sources of confusion in intensive therapy unit alarms. In N. A. Stanton (Ed.), Human factors and alarm design (pp. 207-219). London: Taylor \& Francis.

Momtahan, K. L., Tansley, B. W., \& Hetu, R. (1993). Audibility and identification of auditory alarms in the operating room and intensive care unit. Ergonomics, 36, 1159-76.

Moran, T. P., \& Anderson, R. J. (1990). The workaday world as a paradigm for CSCW design. In Proceedings of CSCW 90 (pp. 381-393). New York: ACM Press.

Patterson, R. D. (1982). Review of the auditory warning system proposed in ARINC 726. Civil Aviation Authority Contract Report 7D/S/0260/3.

Patterson, R. D., Edworty, J., Shailer, M. J., Lower, M. C., \& Wheeler, P. D. (1986). Alarm sounds for medical equipment in intensive care areas and operating theatres. (Institute of Sound and Vibration Research, Report No. AC598). Southampton, UK: Institute of Sound and Vibration Research.

Pedersen, E., \& Sokoler, T. (1997). AROMA-Abstract representation of presence for the purpose of mutual awareness. In Proceedings of $\mathrm{CHI} 97$ Conference (pp. 51-58). New York: ACM Press

Ruhleder, K., \& Jordan, B. (1997). Capturing complex, distributed activities: Video-based interaction analysis as a component of workplace ethnography. (IRL Report). Palo Alto, CA: Institute for Research on Learning.

Sánchez Svensson, M., Tap, H., \& Selling Sjöberg, A. (2000). Localization, orientation and recognition of alarms. A comparison between three alarm systems in use. In J. Gulliksen, A. Lantz, L. Oestreicher, \& K. Sverinson Eklundh (Eds.), Proceedings from NordiCHI 2000. Stockholm: STIMDI.

Sawhney, N., \& Schmandt, C. (1998). Speaking and listening on the run: Design for wearable audio compting. Proceedings of the Second International Symposium on Wearable Computing (ISWC'98), 108-115.

Seagull, F. J., \& Sanderson, P. M. (1998). Anesthsia alarms in surgical context. In Proceedings of the 42nd Annual Meeting of the Human Factors and Ergonomics Society (pp. 1048-1052). Santa Monica, CA: Human Factors and Ergonomics Society.

Spreitzer, M. \& Theimer, M. (1993). Providing location information in a ubiquitous computing environment. Proceedings of the fourteenth ACM symposium on operating systems principles, 270-283.

Stanton, N. A. (1994). Human factors in alarm design. London: Taylor \& Francis.

Streitz, N., Geissler, J., \& Holmer, T. (1998). Roomware for cooperative buildings: Integrated design of architectural spaces and information spaces. In Proceedings of the first conference on cooperative buildings (CoBuild '98) (pp. 120-127). Heidelberg: Springer.

Tap, H., \& Svensson, M. (1999). Understanding alarms: The first step in the development of an alarm system. Proceedings of the $23^{\text {rd }}$ IRIS (Information systems research seminar in Scandinavia) conference, 1999.

Weiser, M. (1991). The computer for the twenty-first century. Scientific American, 265, 94-104.

Weiser, M., \& Brown, J.-S. (1997). The coming age of calm technology. In P. J. Denning \& R. M. Metcalfe (Eds.), Beyond calculation: The next fifty years of computing. New York: Springer-Verlag.

Wellner, P., Mackay, W., \& Gold, R. (1993). Computer augmented environments: Back to the real world. Communications of the ACM, 36 .

Woods, D. D. (1995). The alarm problem and direct attention in dynamic fault management. Ergonomics, 38, 2371-2393. 
Copyright $@ 2003$ EBSCO Publishing 
Copyright $\odot 2003$ EBSCO Publishing 